\title{
A INTERVENÇÃO DO JUDICIÁRIO NAS DECISÕES DA ASSEMBLEIA GERAL DE CREDORES QUE DELIBERAM SOBRE A CONCESSÃO A RECUPERAÇÃO JUDICIAL
}

\section{LA INTERVENCIÓN JUDICIAL EN LAS DECISIONES DE LA JUNTA GENERAL DE ACREEDORES QUE DELIBERAN SOBRE LA CONCESIÓN DE LA RECUPERACIÓN JUDICIAL}

\author{
${ }^{1}$ Cláudia de Lurdes da Silva Gonçalves
}

\section{RESUMO}

A lei 11.101/2005, que disciplina a recuperação judicial, extrajudicial e falência, tal como foi escrita, leva-nos a uma leitura taxativa. Em um primeiro momento podemos crer que não haverá intervenção do judiciário, quanto as decisões proferidas pela Assembleia Geral de Credores. Entretanto, como se verá adiante, a jurisprudência tem tratado a intervenção do judiciário de modo diverso do previsto em lei. O objetivo deste ensaio é buscarmos entender os motivos que fundamentam as intervenções e as qualidades das mesmas. A presente pesquisa se desenvolveu através do método de interpretação sistêmico, tendo na sua base além do estudo da lei própria a análise da jurisprudência.

Palavras-chave: Recuperação judicial, Intervenção judicial, Limites da intervenção, Princípios da lei 11.101/2005

\section{ABSTRACT}

La Ley 11.101/2005, que regula sobre la recuperación judicial, extrajudicial y falencia, de la manera como está escrita, nos lleva una lectura taxativa. En un primer momento nos lleva a creer que no habrá intervención del poder judicial sobre las decisiones tomadas por la Junta de Acreedores. Sin embargo, como veremos más adelante, la jurisprudencia se ha ocupado sobre la intervención del poder judicial de una manera diferente de lo que está previsto en ley. El propósito de este ensayo es tratar de comprender las razones que fundamentan las intervenciones y sus cualidades. Esta investigación se desarrolló a través del método de interpretación sistémica, teniendo en su base tanto el estudio de la propia ley, como también una análisis de la jurisprudencia.

Keywords: Recuperación judicial, Intervención judicial, Límites de la intervención, Principios de la ley 11.101/2005

\footnotetext{
${ }^{1}$ Mestra em Direito Empresarial pela Faculdade de Direito Milton Campos, FDMC, Minas Gerais, MG, (Brasil). $1^{\text {a }}$ Escrevente de Registro de Imóveis e Anexos de Taquaritinga/SP, RITDPJ, São Paulo.(Brasil). E-mail: carolina.catizane@gmail.com 


\section{INTRODUÇÃO}

Ao estudarmos a lei 11.101/2005, podemos observar a taxatividade da lei e até mesmo vedações à interferência do judiciário sobre a possibilidade de concessão da recuperação judicial.

Inconformados com a letra da lei partiu-se em busca do posicionamento jurisprudencial, onde encontramos suporte para propositura do presente trabalho.

A pesquisa na busca opções para solução da questão. Apesar de a lei não prever a intervenção do juiz nas decisões da assembleia -que o diploma legal estatui como soberana-, a atuação judicial pode ser fundamental para o destino da empresa. É pertinente a pretensão de um processo justo, o que vai além da simples aplicação literal do regulamento. $\mathrm{O}$ ensaio, desenvolver-se-á por meio do estudo da jurisprudência e da analise sistêmica da lei.

\section{OS CENÁRIOS PROPOSTOS PARA REFLEXÃO: PODE O JUDICIÁRIO INTERVIR NA DECISÃO DA ASSEMBLEIA GERAL DE CREDORES QUE REJEITA OU APROVA O PLANO DE PAGAMENTO?}

A presente reflexão limitar-se-á a analisar duas situações em que a jurisprudência tem tomado posicionamento diverso do previsto em lei. No primeiro cenário, a assembleia geral dos credores decide aprovar um plano de pagamento, mas o juízo se recusa a homologar o decidido. No segundo, a decisão da assembleia geral de credores é contraria à concessão da recuperação judicial, mas o juiz da causa homologa o plano de pagamento, concedendo a recuperação judicial, mesmo que não esteja presente os requisitos do cram down.

Quais são os limites da revisão judicial de decisões da assembleia geral de credores?

Para trabalharmos as hipóteses, buscamos investigar a situação na perspectiva de dois cenários encontrados na jurisprudência atualmente e os argumentos utilizados para embasar cada tipo de decisão.

\section{A ANÁlise dos CENÁRIOS PROPOSTOS E A MOtivaÇão PARA INTERVENÇÃO}


O primeiro cenário concerne ao caso de um plano de recuperação que fora aprovado em assembleia geral de credores. Contudo, o juiz não homologa tal decisão, pedindo que seja apresentado e posto em votação um novo plano de recuperação.

Diante do cenário acima exposto, devemos pensar quais os motivos norteadores da decisão. Analisando os julgados proferidos, extraímos as seguintes motivações:

1)Algumas decisões foram motivadas com base no princípio da discricionariedade ${ }^{1}$, que tem como base oportunidade e conveniência.

2) De outra banda, temos decisões motivadas com base na validade do negócio jurídico $^{2}$, considerando que alguma das cláusulas do plano de pagamento tenha afrontado o artigo 104 do código civil.

O segundo cenário presente na jurisprudência tange à decisão da assembleia geral de credores que não aprova o plano de pagamento, por não atingir o quórum qualificado exigido pela lei 11.101/2005 no artigo 45.

A lei nesse caso prevê a convolação da recuperação judicial em falência, conforme artigo 73, inciso III da lei 11.101/2005. Entretanto o julgador decide de forma contrária concedendo a recuperação judicial, e o faz pelos seguintes motivos:

\footnotetext{
${ }^{1}$ Sobre discricionariedade, importante os ensinamentos de José Roberto dos Santos Bedaque, em BEDAQUE, Jose Roberto dos Santos. In: MARCATO, Antonio Carlos (Coord.). Código de processo civil interpretado. São Paulo: Atlas, 2004. p. 352- 354. "Quanto maior a indeterminação do conceito legal, mais relevante e delicada apresenta-se a função jurisdicional. A decisão, nesses casos, pressupõe grande liberdade de investigação crítica do julgador, que a doutrina processual costuma identificar, de forma não muito precisa, como poder discricionário atribuído ao juiz. Na realidade, não se trata de poder discricionário, visto que o juiz, ao decidir à luz dessas regras, não o faz por conveniência e oportunidade, juízos de valor próprios da discricionariedade."

${ }^{2}$ Sobre a motivação amparada na validade de negócio jurídico, para melhor entendimento exemplo ilustrativo proferido Egregio Tribunal de Justiça de São Paulo. Brasil. Tribunal de Justiça de São Paulo. Acódrão no Agravo de Instrumento $\mathrm{n}^{\circ}$ 2118641-25.2014.8.26.0000. Relator: Oliveira filho, PAULO FURTADO DE. Julgado em 12.08.2015. Disponível em: https://esaj.tjsp.jus.br/cjsg/getArquivo.do?cdAcordao=8715308\&cdForo=0\&vlCaptcha=jrvhf. Acessado em 23.08.2015.
} 
1) Nesse caso o magistrado usa como motivação do cram down, instituto previsto no artigo 58 da lei $11.101 / 2005^{3}$, que possibilita a concessão com um quórum menos exigente que o quórum qualificado. Mas há ainda casos em que o julgado promove um rebaixamento do cram down ${ }^{4}$ para que seja possível a concessão da recuperação judicial, normalmente nos casos em que apenas um credor detém o poder de vetar a recuperação judicial.

2) Há também na jurisprudência decisões motivadas no princípio da preservação da empresa $^{5}$, expresso no artigo 47 da lei 11.101/2005. O juiz decide homologar a recuperação judicial, para que se cumpra o próprio escopo da lei, definido em seus objetivos qual seja, a preservação da empresa ${ }^{6}$, sua função social e o estimulo à atividade econômica;

\footnotetext{
${ }^{3}$ Nesse sentido a observação tecido por Carlos Klein Zanini em ZANIN, Carlos Klein. In: SOUZA JUNIOR, Francisco Satiro de; PITOMBO, Antonio Sergio A. de Moraes (Coord.). Comentários à lei de recuperação de empresas e falências. 2. ed. São Paulo: Revista dos Tribunais, 2007. p. 334: "Deve-se atentar, todavia, para o fato de que a própria Lei prevê uma alternativa à decretação automática da falência pela rejeição do Plano na Assembleia-Geral de Credores. Trata-se da possibilidade prevista no art. $58, \S 1^{\circ}$, da Lei, segundo o qual assiste ao juiz a prerrogativa ('o juiz poderá...') de 'conceder a recuperação judicial com base no Plano que não obteve aprovação' na Assembleia, uma vez atendidas as condicionantes listadas em ambos parágrafos desse dispositivo. Por conseguinte, não é a mera rejeição do Plano pela Assembleia condição de per se bastante para decretação da quebra. Há de se conceder ao devedor, previamente, o benefício da segunda chance estampado no art. 58 da Lei, sujeito ao prudente arbítrio do juiz da causa.'

${ }^{4}$ Para exemplificar o rebaixamento do CRAM DOWN, de grande valia o acórdão: RIO GRANDE SUL. Tribunal de Justiça do Estado do Rio Grande Sul. Agravo de Instrumento n. 70045411832. Agravante: Banco do Brasil S/A. Agravado: Aeromot Industria Mecanico Metalurgica Ltda. Relator Romeu Marques Ribeiro Filho Disponível em:<http://google8.tj.rs.gov.br/search?q=cache:www1.tjrs.jus.br/site_php/consulta/consulta_processo.php\%3Fn ome_comarca\%3DTribunal\%2Bde\%2BJusti\%25E7a\%26versao\%3D\%26versao_fonetica\%3D1\%26tipo\%3D1\% 26id_comarca\%3D700\%26num_processo_mask\%3D70045411832\%26num_processo\%3D70045411832\%26co dEmenta\%3D4575906+INSTRUMENTO+DESPROVIDO.+++AGRAVO+DE+INSTRUMENTO+QUINTA+C $\% \mathrm{C} 3 \% 82 \mathrm{MARA}+\mathrm{C} \% \mathrm{C} 3 \% \mathrm{E} 7 \mathrm{VEL}+\mathrm{N} \% \mathrm{C} 2 \% \mathrm{BA}+70045411832+\% 09 \mathrm{COMARCA}+\mathrm{DE}+\mathrm{PORTO}+\mathrm{ALEGRE} \&$ sit $\mathrm{e}=$ ementario\&client=buscaTJ\&access $=$ p $\& \mathrm{ie}=\mathrm{UTF}-8 \&$ proxystylesheet $=$ buscaTJ\&output $=$ xml_no_dtd\&oe=UTF$8 \&$ numProc $=70045411832 \&$ comarca $=$ Comarca+ $\quad$ de+Porto $\quad$ +Alegre \&dtJulg=29-02-2012\& relator=Romeu+Marques+Ribeiro+Filho >. Acesso em: 13 nov. 14.

${ }^{5}$ Nesse sentindo julgado do Egregio Tribunal de Justiça do Rio Grande do Sul: AGRAVO DE INSTRUMENTO. RECUPERAÇÃO JUDICIAL. HOMOLOGAÇÃO DA DECISÃO QUE APROVOU O PLANO. PRINCÍPIO DA PRESERVAÇÃO DA EMPRESA. (...) 4.Ressalte-se que cabe ao Judiciário aferir sobre a regularidade do processo decisório da Assembléia de Credores, se esta foi realizada de forma adequada e foram atendidos os requisitos legais necessários para tanto, levando-se em consideração, ainda, a viabilidade econômica de a empresa cumprir o plano ajustado, ou mesmo se há a imposição de sacrifício maior aos credores, para só então proferir decisão concedendo ou não a recuperação judicial à empresa agravada, pressupostos que foram observados no caso dos autos. 5.Ademais, 0 princípio da preservacão da empresa, insculpido no art. 47 da Lei 11.101/2005, dispõe que a recuperacão judicial tem por objetivo viabilizar a superacão da situacão de crise econômico-financeira do devedor, a fim de permitir a manutencão da fonte produtora, do emprego dos trabalhadores e dos interesses dos credores, promovendo, assim, a preservacão daquela. sua funcão social e o estímulo à atividade econômica. 6.Assim, observadas as peculiaridades do caso em concreto, onde entendo que restaram preenchidos os requisitos legais atinentes ao ato de convocação para a assembléia geral de credores no procedimento de recuperação judicial, presente o fato de que por ocasião da realização do referido ato o Plano de Recuperação Judicial restou aprovado, nos termos do art. 45 do diploma legal precitado, bem como em consonância com o princípio da preservação da empresa, norte balizador presente na novel lei que trata da insolvência corporativa, a manutenção da decisão agravada que concedeu a recuperação judicial, é a medida que se impõe.
} 
Ambos os cenários refletem a interferência do juiz sobre a decisão proposta pela assembleia geral de credores. No entanto, a jurisprudência busca solucionar o problema com base em argumentos diversos, como demonstrado em cada subitem.

\section{A INVESTIGAÇÃO DA MOTIVAÇÃO E SUA QUALIDADE}

A proposta deste ensaio concerne na investigação da qualidade da motivação adotada pelos julgadores. E, ainda, identificar outros motivos possíveis para justificar a decisão desta natureza.

Partiremos para resposta do problema com a análise da lei 11.101/2005, de seus princípios e a conformidade das decisões da assembleia geral de credores com o ordenamentojurídico.

7. Por fim, é de se destacar que a recuperacão judicial se trata de um favor creditício, de sorte que deve prevalecer o princípio da relevância do interesse dos credores, ou seja, a vontade majoritária destes no sentido de que o custo individual a ser suportado pelos mesmos é menor do que o benefício social que advirá à coletividade com a aprovacão do plano de recuperacão, preservando com isso a atividade empresarial, em última análise, o parque industrial ou mercantil de determinada empresa. bem como os empregos que esta mantém para geracão da riqueza de um país. Rejeitada a preliminar contra-recursal e, no mérito, negado provimento ao agravo de instrumento. (Agravo de Instrumento $\mathrm{N}^{\circ}$ 70043514256, Quinta Câmara Cível, Tribunal de Justiça do RS, Relator: Jorge Luiz Lopes do Canto, Julgado em 31/08/2011).

${ }^{6}$ Para melhor ilustração sobre o ponto, importante a leitura da decisão do Egrégio Tribunal de Justiça do Estado do Rio Grande do Sul, que nos apresenta a seguinte ementa: AGRAVO DE INSTRUMENTO. CONCESSÃO DA RECUPERAÇÃO JUDICIAL. 'CRAM DOWN'. PRINCÍPIO DA PRESERVAÇÃO DA EMPRESA. Decisão que tem por finalidade assegurar a possibilidade de superação da situação de crise econômico-financeira da agravada, permitindo a manutenção da fonte produtora, do emprego dos trabalhadores e dos interesses dos credores, promovendo, assim, a preservação da empresa, sua função social e o estímulo à atividade econômica. Manutenção da decisão recorrida. NEGARAM PROVIMENTO AO RECURSO. Disponível em: RIO GRANDE DO SUL. Tribunal de Justiça. Agravo de Instrumento n. 70048350169. Agravante: Banco do Brasil S/A Agravado: Brasfumo Industria Brasileira de Fumo S.A. Relator: Des. ${ }^{a}$ Isabel Dias Almeida. Porto Alegre, 27 de junho de 2012. Disponível em: <http://google8.tj.rs.gov.br/search?q=cache:www1.tjrs.jus.br/site_php/consulta/consulta_processo.php\%3Fno me_comarca\%3DTribunal\%2Bde\%2BJusti\%25E7a\%26versao\%3D\%26versao_fonetica\%3D1\%26tipo\%3D1 \%26id_comarca\%3D700\%26num_processo_mask\%3D70048350169\%26num_processo\%3D70048350169\%2 6codEmenta\%3D4775727+Agravo+de+Instrumento+N\%C2\%BA+70048350169\%2C+Quinta+C\%C3\% A2ma $\mathrm{ra}+\mathrm{C} \% \mathrm{C} 3 \% \mathrm{ADvel} \% 2 \mathrm{C}+\mathrm{Tribunal}+\mathrm{de}+\mathrm{Justi} \% \mathrm{C} 3 \% \mathrm{~A} 7 \mathrm{a}+\mathrm{do}+\mathrm{RS} \% 2 \mathrm{C}+\&$ site=ementario\&client=buscaTJ\&acces $\mathrm{s}=$ p\&ie $=U T F \&$ proxystylesheet $=$ buscaTJ\&output $=x m l \_n o \_d t d \& o e=U T F 8 \&$ numProc $=70048350169 \&$ comarca $=$ Comarca + de + Ven\%E2ncio+Aires\&dtJ ulg=27-06-2012\& relator=Isabel+Dias+Almeida $>$. Acesso em: 20 nov. 2012. 
O presente exame decorre da percepção de existir incerteza, diante das múltiplas possibilidades envolvendo o instituto da recuperação judicial de empresa: com frequência, sociedades veem-se forçadas a buscar a proteção do instituto. A Lei 11.101/2005, que regula a matéria, mostra-se insuficiente como instrumento para tutelar adequadamente a pluralidade de sujeitos que costumam estar em tal circunstância; e a análise da jurisprudência, por seu turno, revela a expansão da interferência do Poder Judiciário frente às decisões proferidas pelas nas assembleias de credores.

Um exame preliminar da matéria põe em evidência cinco razões que abonam a pesquisa. É o que se vê a seguir.

A primeira razão concerne ao caráter taxativo do texto legal. A Lei 11.101/2005 prescreve as decisões do juiz, disciplinando de modo restrito, isto é, predeterminando um rol taxativo de alternativas decisórias. Assim, pela leitura simples de seus dispositivos, encontramse as seguintes imposições:

Art. 58. Cumpridas as exigências desta Lei, o juiz concederá a recuperacão judicial do devedor cujo plano não tenha sofrido objeção de credor nos termos do art. 55 desta Lei ou tenha sido aprovado pela assembléia-geral de credores na forma do art. 45 desta Lei. [...]. (grifo nosso)

Art. 73. 0 iuiz decretará a falência durante o processo de recuperação judicial: [...]. (grifo nosso).

Portanto, ao conceber um regulamento para a recuperação judicial de empresa, o legislador foi imperativo, inflexível, aparentemente pretendendo engessar os movimentos do julgador. $^{7}$

\footnotetext{
${ }^{7}$ Discricionariedade no processo civil, ler Luis Alberto Reichel. Em: REICHELT, Luis Alberto. A prova no direito processual civil. Porto Alegre: Livraria do Advogado, 2009. p. 332." A correta compreensão do alcance do comando acima referido impõe reconhecer, antes de tudo, que a atuação jurisdicional em sede de instrução processual de forma alguma pode ser tida como discricionária. Não se deve confundir discricionariedade com margem de interpretação: ao juiz não se dá, em tais comandos, a possibilidade de decidir exclusivamente com base no binômio conveniência/oportunidade; ao contrário, o que há é uma situação na qual o julgador está sujeito a um regramento jurídico que predetermina as hipóteses nas quais é permitida a sua intervenção e, ao mesmo tempo, estabelece as consequências que a ela vêm associadas. O problema a ser enfrentado, em verdade, é o da determinação do significado da linguagem empregada em tais hipóteses e consequências, que não raro, acaba sendo definido à luz dos fatores presentes no caso concreto.
} 
Pontuamos a necessidade de proceder-se um exame dos conceitos fechados existentes na lei - o que vem a ser, aliás, condição para o desenvolvimento de outros tópicos. Nesse sentido, os ensinamentos de Eduardo Secchi Munhoz ${ }^{8}$, que afirma não haver na lei conceitos abertos que possam configurar margem de interpretação; não havendo, pois, para o julgador, a hipótese de um juízo de discricionariedade, in verbis:

\begin{abstract}
Não cabe ao juiz, portanto, nenhuma margem de discricionariedade a respeito da matéria ou, em palavras mais precisas, não há na lei, quanto a esse aspecto, conceitos abertos (chamados conceitos indeterminados) que confiram ao juiz margem ampla de interpretação para emissão dos respectivos juízos de legalidade. Assim, uma vez preenchidos os requisitos da lei, que nesse aspecto não adota nenhuma cláusula aberta ou conceito indeterminado, e aprovado o plano pelos credores, cumpre ao ¿uiz conceder a recuperacão: se, por outro lado, não se configurar tal hipótese. cabe ao juiz decretar a falência.
\end{abstract}

Uma segunda razão são os princípios norteadores da lei 11.101/2005, expostos no parecer 534/2004 do Senador Ramez Tebet, quais sejam:

1) Preservação da empresa;

2) Separação dos conceitos de empresa e de empresário;

3) Recuperação das sociedades e empresários recuperáveis;

4) Retirada do mercado de sociedades ou empresários não recuperáveis;

5) Proteção aos trabalhadores;

6) Redução do custo do crédito no Brasil;

7) Celeridade e eficiência dos processos judiciais;

8) Segurança jurídica;

9) Participação ativa dos credores;

10) Maximização do valor dos ativos do falido;

11) Desburocratização da recuperação de microempresas e empresas de pequeno porte;

12) Rigor na punição de crimes relacionados à falência e à recuperação judicial;

O presente trabalho dará atenção apenas àqueles princípios que guardam relação com a abordagem proposta, isto é, a preservação da empresa; recuperação das sociedades e empresários recuperáveis; retirada do mercado de sociedades ou empresários não recuperáveis;

8 MUNHOZ, Eduardo Secchi. In: SOUZA JUNIOR, Francisco Satiro de; PITOMBO, Antonio Sergio A. de Moraes (Coord.). Comentários à lei de recuperação de empresas e falências. 2. ed. São Paulo: Revista dos Tribunais, 2007. p. 287.

${ }^{9}$ Sobre os princípios da lei 11.101/2005, ver Medeiros, Felipe Dia. Princípios Norteadores Da Recuperação Judicial: Importância Desta Análise No Brasil. 
celeridade e eficiência dos processos judiciais; segurança jurídica; e participação ativa dos credores.

No ponto, importante transcrever os ensinamentos de João Pedro Scalzilli, Rodrigo Tellechea e Luis Felipe Spinelli ${ }^{10}$, in verbis:

\begin{abstract}
"Quanto à aplicação dos princípios, note-se, entretanto, que nem sempre será possível atendê-los de forma harmônica e conjunta, especialmente quando vierem a conflitar entre si, situacão na qual deverá o interprete da lei realizar o devido sopesamento entre os princípios, levando-se em consideração o caso jurídico em concreto e as consequências socioeconômicas da eventual decisão."
\end{abstract}

A terceira motivação é a necessidade de discutir-se a soberania da assembleia geral de credores. Ora, logo que surgiu a Lei 11.101/2005, as decisões judiciais não discutiam a soberania da assembleia geral de credores, mas seguiam à risca a previsão legal. ${ }^{11} \mathrm{As}$ deliberações da assembleia eram soberanas, restando ao juiz unicamente homologar a recuperação judicial ou, noutro sentido, designar a falência da sociedade, únicas hipóteses previstas pela lei.

Entretanto, nas pesquisas jurisprudenciais, observa-se que a proposta de lei em relação à votação em classes e o quórum qualitativo e quantitativo podem levar a situações que um único credor poderia inviabilizar a recuperação judicial. A partir dessa perspectiva a jurisprudência começou a flexibilizar a regra do cram down.

10 SCALZILLI, João Pedro; TELECHEA, Rodrigo; SPINELLI, Luis Felipe. Objetivos e princípios da lei de falências e recuperação de empresas. Revista Síntese Direito Empresarial, São Paulo, ano 5, n. 26, maio/jun. 2012.

${ }^{11}$ Nesse caminho o entendimento de Alberto Caminã Moreira, em : MOREIRA, Alberto Caminã. Poderes da assembléia de credores, do juiz e atividade do ministério público. São Paulo In: VALENTE, Luiz Fernando (Coord.). Direito falimentar e nova lei de falências e recuperação de empresas: Quartier Latin, 2005. p. 256. "Rejeitar o plano é papel conferido exclusivamente à assembleia; declarar a falência é ato exclusivamente jurisdicional. Ao receber a ata da assembleia, contendo a decisão de rejeitar o plano, o juiz deve prolatar a sentença declaratória de falência, atendidos os requisitos do art. 99. A declaracão de falência é consequência imediata da decisão da assembleia de rejeicão do plano. Não há outro caminho procedimental a ser seguido. (grifo nosso)." 
Nessa toada, considerações importantes sobre a aplicação do cram down podem ser observadas no julgamento em exame, no voto do Desembargador Relator Romeu Marques Ribeiro Filho ${ }^{12}$, in verbis:

\begin{abstract}
Não escapa que na Assembléia de Credores o plano foi aprovado por duas de suas classes, os trabalhistas e quirografários, sendo rejeitado pelos de garantia real, o que, nos termos do art. 45 da Lei de Recuperação Judicial, levou à aplicabilidade do quanto disposto no inc. III do $\S 1^{\circ}$ do art. 58 da Lei de Falências. É certo que a previsão do mencionado art. 58 foi abrandada pelo digno Juízo singular, sob pena de restar inviabilizada a aprovacão do plano, haja vista, como iá referido, apenas dois credores estarem contemplados na classe em que o Banco do Brasil S/A detém crédito sobejamente superior. (grifo nosso)
\end{abstract}

A intervenção o juiz na aplicação da regra do cram down ganha mais relevância ainda a partir da Lei Complementar 147 publicada em agosto de 2014, que cria a $4^{\mathrm{a}}$ classe de credores. Com a criação da $4^{\mathrm{a}}$, sem a alteração do artigo 58 da lei 11.101/2005 que estipula a regra do cram down, poderá haver empate nas votações e nesse caso cria mais um problema a ser resolvido através da intervenção judicial.

A quarta motivação pode traduzir-se como um imperativo de atualidade. Ora, a realidade não é estática; pelo contrário, mais do que em qualquer outra época, vive-se numa sociedade caracterizada por mudanças rápidas e frequentes. Por óbvio, as relações empresariais igualmente modificam-se conforme as variações do mercado econômico. Frise-se que tampouco o direito é estático. Assim, ao presente estudo, interessa as consequências que uma falência pode representar para uma determinada cidade ou setor da economia, bem como a repercussão da aprovação de um plano de pagamento que viole a legalidade.

Seguindo esta trilha, a vinculação do insucesso da recuperação judicial com a falência é um grande erro do legislador, como bem pontuou Fabio Ulhoa Coelho ${ }^{13}$ :

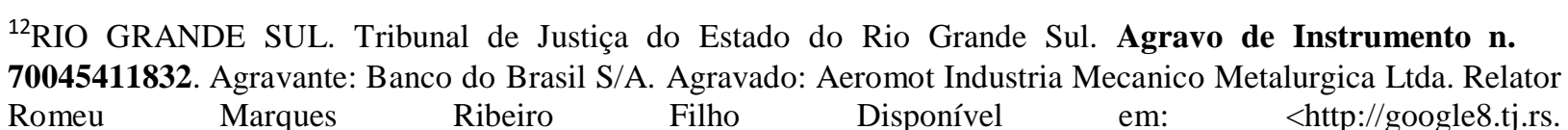
$\begin{array}{lllll}\text { Romeu Marques } & \text { Ribeiro } & \text { Filho } & \text { Disponível } & \text { em: } \\ \text { gov.br/search?q=cache:www1.tjrs.jus.br/site_php/consulta/consulta_processo.php\%3Fnome_comarca\%3DTri }\end{array}$ bunal\%2Bde\%2BJusti\%25E7a\%26versao\%3D\%26versao_fonetica\%3D1\%26tipo\%3D1\%26id_comarca\%3D 700\%26num_processo_mask\%3D70045411832\%26num_processo\%3D70045411832\%26codEmenta\%3D45 75906+INSTRUMENTO+DESPROVIDO.+++AGRAVO+DE+INSTRUMENTO+QUINTA+C\%C3\%82MA $\mathrm{RA}+\mathrm{C} \% \mathrm{C} 3 \% \mathrm{E} 7 \mathrm{VEL}+\mathrm{N} \% \mathrm{C} 2 \% \mathrm{BA}+70045411832+\% 09 \mathrm{COMARCA}+\mathrm{DE}+\mathrm{PORTO}+\mathrm{ALEGRE} \&$ site=ementari o\&client $=$ buscaTJ\&access $=$ p $\&$ ie $=U T F-8 \&$ proxystylesheet $=\quad$ buscaTJ\&output=xml_no_dtd\&oe=UTF$8 \&$ numProc $=70045411832 \&$ comarca $=$ Comarca+ de+Porto $\quad$ +Alegre $\&$ dtJulg=29-02-2012\& relator=Romeu+Marques+Ribeiro+Filho>. Acesso em: 13 nov. 12.

13 (Coelho, 2010, p. 222). 
“A vinculação do insucesso da recuperação judicial à decretação da falência não deveria existir. Ela propicia o uso fraudulento do instituto por devedores que não se encontram em estado pré-falimentar e apenas desejam locupletar-se às custas dos credores."

De outra banda, mas ainda sobre a convolação da recuperação judicial em falência, importante o entendimento de Luiz Inácio Vigil Neto ${ }^{14}$ que segue o mesmo raciocínio do inciso II, para interpretar o inciso III do artigo 73 da mesma lei. No ponto, indaga o autor: "como é possível sustentar a transformação do estado de recuperação judicial para falência, se o devedor ainda não estava juridicamente em recuperação judicial?" Para ele, não poderia ser convolada a recuperação judicial em falência nas hipóteses dos incisos II e III supracitados, por não haver ainda o deferimento da recuperação propriamente dito.

Como quinto argumento, temos que analisar o uso do benefício da recuperação judicial sobre outra perspectiva, temos os casos em que os devedores tentam utilizar o instituto da recuperação judicial com intuito fraudulento ou com o objetivo de causar prejuízo direto aos credores, impondo-lhes um ônus muito além do suportável em uma situação de crise. Para demonstrar tal situação, trazemos à baila o seguinte julgado proferido pelo Egrégio Tribunal de São Paulo ${ }^{15}$ :

Agravo. Recuperação Judicial. Plano aprovado pela assembleia-geral de credores. Plano que prevê o pagamento do passivo em 18 anos, calculando-se os pagamentos em percentuais $(2,3 \%, 2,5 \%$ e $3 \%)$ incidentes sobre a receita líquida da empresa, iniciando-se os pagamentos a partir do $3^{\circ}$ ano contado da aprovação. Previsão de pagamento por cabeça até o $6^{\circ}$ ano, acarretando pagamento antecipado dos menores credores, instituindo conflitos de interesses entre os credores da mesma classe. Pagamentos sem incidência de juros. Previsão de remissão ou anistia dos saldos devedores caso, após os pagamentos do $18^{\circ}$ ano, não haja recebimento integral. Proposta que viola os princípios gerais do direito, os princípios constitucionais da isonomia, da legalidade, da propriedade, da proporcionalidade e da razoabilidade, em especial o princípio da 'pars conditio creditorum' e normas de ordem pública. Previsão que permite a manipulação do resultado das deliberações assembleares. Falta de discriminação dos valores de cada parcela a ser paga que impede a aferição do cumprimento do plano e sua execução específica, haja vista a falta de liquidez e certeza do 'quantum' a ser pago. Ilegalidade da cláusula que estabelece o pagamento dos credores quirografários e com garantia real após o decurso do prazo bienal da

. 14 (Neto, 2008).

15SÃO PAULO. Tribunal de Justiça. Acórdão em Agravo de Instrumento n. 0136362-29.2011.8.26.0000.

Relator: Pereira Calças. São Paulo, 28 de fevereiro de 2012. Disponível em: <https://esaj.tjsp.jus.br/cjsg/getArquivo.do?cd Acordao=5709697\&vlCaptcha=vvxtu> Acesso em: 13 nov. 2012 
supervisão judicial (art. 61, 'caput', da Lei no 11.101/2005). Invalidade (nulidade) da deliberacão da assembleia-geral de credores declarada de ofício, com determinacão de apresentacão de outro plano, no prazo de 30 dias, a ser elaborado em consonância com a Constituicão Federal e Lei ${ }^{0}$ 11.101/2005, a ser submetido à assembleia-geral de credores em 60 dias, sob pena de decreto de falência. (grifo do nosso).

Este acórdão foi proferido em 2012, momento em que se iniciou um novo posicionamento da jurisprudência.

Nesse sentido, ratificando o entendimento firmado pelo Egrégio Tribunal de São Paulo, Mandando de Segurança ${ }^{16}$ julgado recentemente:

AGRAVO REGIMENTAL. Análise prejudicada em razão do julgamento do mérito do Mandado de Segurança. MANDADO DE SEGURANÇA. Impetração contra Desembargador Relator que deferiu liminar de suspensão dos efeitos da homologação do plano de recuperação judicial. Ausência de recurso específico contra tal decisão, dada a sua natureza provisória, a viger tão somente até o julgamento de mérito do Agravo de Instrumento, mas que não implica em cabimento automático do writ. Medidas de exclusivo critério do relator, na formação de sua convicção e afeto ao princípio da discricionariedade do Magistrado. Apenas e tão somente em caráter exceptivo, caberia o mandado de segurança para atacar decisões teratológicas, causadoras de dano grave e irreversível a direito líquido e certo da parte. Inexistência de direito líquido e certo vulnerado pela decisão judicial. Câmara Reservada de Direito Empresarial, de forma reiterada, tem admitido que a aprovacão do plano de recuperacão judicial pela assembleia de credores não a torna imune à verificacão. pelo Poder Judiciário, sobre aspectos de sua legalidade e de obediência a princípios cogentes que iluminam o direito contratual. Extinção do processo.

16 São Paulo. Tribunal de Justiça. Mandado de Segurança n. 0096809.04.2013.8.26.0000. Relator: Francisco Loureiro. São Paulo, 15 de agosto de 2013. Disponível em http://esaj.tjsp.jus.br/cpo/sg/search.do?paginaConsulta=1\&localPesquisa.cdLocal=-

$1 \&$ cbPesquisa=NUMPROC \& tipoNuProcesso=UNIFICADO\&numeroDigitoAnoUnificado=0096809

04.2013\&foroNumeroUnificado $=0000 \&$ dePesquisaNuUnificado $=0096809$ -

04.2013.8.26.0000\&dePesquisa=\&pbEnviar=Pesquisar 


\section{CONCLUSÃO}

A questão provavelmente passa por uma construção a ser produzida com à análise da lei 11.101/2005, do direito, do processo civil e do ordenamento jurídico de forma geral.

Nesse sentindo, observamos os ensinamentos de Rafael de Freitas Valle Dresch ${ }^{17}$, in verbis:

[...] cabe analisar se o poder definidor dos caminhos da recuperação não acaba por passar pelo crivo do poder do juiz, não somente formal, mas substancial, ante as normas gerais do direito da empresa, do direito privado e do direito como um todo.

A lei 11.101/2005 veem sendo modificada, desde seu nascimento, pela jurisprudência. As modificações são necessárias para que tenhamos uma aplicação mais justa do instituto de modo geral. Contudo, as interferências ${ }^{18}$ devem ser motivadas, tendo como base de sua motivação a busca pelo processo justo fazendo com que assim possa ser atingido o escopo da lei, baseado nos princípios que a norteia em conjunto com o ordenamento jurídico cogente.

Sobre a limitação da intervenção do judiciário de grande importância o informativo $\mathrm{n}^{\circ}$ 0549 Período: 05 de novembro de 2014 que nos apresente o seguinte entendimento sobre o tema:

DIREITO EMPRESARIAL. CONTROLE JUDICIAL DO PLANO DE RECUPERAÇÃO JUDICIAL. Cumpridas as exigências legais, o juiz deve conceder a recuperação judicial do devedor cujo plano tenha sido aprovado em assembleia (art. 58, caput, da Lei 11.101/2005), não lhe sendo dado se imiscuir no aspecto da

\footnotetext{
${ }^{17}$ DRESCH, R. F. V. . Reflexões sobre a função econômico-social frente ao poder dos credores e o poder do juiz na recuperação de empresas. In: Liane Tabarelli Zavascki; Marcia Andrea Buring; Marco Félix Jobim. (Org.). Diálogos Constitucionais de Direito Público e Privado. 1 ed. Porto Alegre, 2012, v. 2, p. 405-420.pag.406.

${ }^{18}$ No que tange a interferência do juiz nas decisões da assembleia, de grande valia os ensinamentos de José Roberto Dos Santos Bedaque, sobre a direção formal e material do processo. Em : BEDAQUE, Jose Roberto dos Santos. In: MARCATO, Antonio Carlos (Coord.). Código de processo civil interpretado. São Paulo: Atlas,2004. p 347348.. "O exercício da atividade jurisdicional pressupõe seja o juiz dotado de poderes, sem o que seria inviável a condução do processo. Iniciado por provação da parte (art. $2^{\circ}$ ), seu desenvolvimento dá-se por impulso oficial (art. 262), devendo o julgador participar ativamente do contraditório, visando possibilitar que o instrumento estatal de solução de controvérsias atinja seus escopos. Para tanto, ao juiz é conferida a direcão não apenas formal, mas material do processo."
} 
viabilidade econômica da empresa. De fato, um vértice sobre o qual se apoia a referida lei é, realmente, a viabilidade econômica da empresa, exigindo-se expressamente que o plano de recuperação contenha demonstrativo nesse sentido (art. 53, II). No entanto, se é verdade que a intervenção judicial no quadrante mercadológico de uma empresa em crise visa tutelar interesses públicos relacionados à sua função social e à manutenção da fonte produtiva e dos postos de trabalho, não é menos certo que a recuperação judicial, com a aprovação do plano, desenvolve-se essencialmente por uma nova relação negocial estabelecida entre o devedor e os credores reunidos em assembleia. Realmente, existe previsão legal para o magistrado conceder, manu militari, a recuperação judicial contra decisão assemblear - cram down ( $\operatorname{art.~58,~} \S 1^{\circ}$ ) -, mas não o inverso, porquanto isso geraria exatamente o fechamento da empresa, com a decretação da falência (art. $56, \S 4^{\circ}$ ), solução que se posiciona exatamente na contramão do propósito declarado da lei. Ademais, o magistrado não é a pessoa mais indicada para aferir a viabilidade econômica de planos de recuperação judicial, sobretudo daqueles que já passaram pelo crivo positivo dos credores em assembleia, haja vista que as projeções de sucesso da empreitada e os diversos graus de tolerância obrigacional recíproca estabelecida entre credores e devedor não são questões propriamente jurídicas, devendo, pois, acomodar-se na seara negocial da recuperação judicial. Assim, o magistrado deve exercer o controle de legalidade do plano de recuperacão - no que se insere o repúdio à fraude e ao abuso de direito -, mas não o controle de sua viabilidade econômica. Nesse sentido, na I Jornada de Direito Comercial CJF/STJ, foram aprovados os Enunciados 44 e 46, que refletem com precisão esse entendimento: 44: “A homologação de plano de recuperação judicial aprovado pelos credores está sujeita ao controle de legalidade"; e 46: "Não compete ao juiz deixar de conceder a recuperação judicial ou de homologar a extrajudicial com fundamento na análise econômico-financeira do plano de recuperação aprovado pelos credores". REsp 1.359.311-SP, Rel. Min. Luis Felipe Salomão, julgado em 9/9/2014.(grifo nosso)

Em suma, o cerne da questão é identificar quais são os limites da revisão judicial de decisões da assembleia geral de credores, com ênfase na qualidade da motivação utilizada pelo magistrado. Como visto, a lei não previa a interferência do judiciário nas decisões da assembleia geral de credores, taxativa, engessando as possibilidades de decisões.

Com o uso do instituo a jurisprudência pacificou a validade da interferência do judiciário nas decisões da assembleia geral de credores, o problema restou quanto a motivação e qualidade da intervenção. O ponto agora é o limite da interferência, para que se respeite os princípios da lei e seu objetivo, tendo em vista que Recuperação Judicial é um processo de negociação entre os credores e devedores, sendo válida a intervenção do judiciário, buscando a aplicação da lei da melhor forma possível, garantindo um processo justo e equânime.

\section{REFERÊNCIAS BIBLIOGRÁFICAS:}

BRASIL. Lei $\mathbf{n}^{0}$ 11.101, de 9 de fevereiro de 2005. Regula a recuperação judicial, a extrajudicial e a falência do empresário e da sociedade empresária. Disponível em: c) (i) (9) 
<http://www.planalto.gov.br/ ccivil_03/_ato2004-2006/2005/lei/l11101.htm>. Acesso em: 31 out. 2013.

COELHO, Fábio Ulhoa. Comentários à lei de falências e recuperação judicial. 7. ed. São Paulo: Saraiva, 2010. p. 222.

DRESCH, R. F. V. Reflexões sobre a função econômico-social frente ao poder dos credores e o poder do juiz na recuperação de empresas. In: Liane Tabarelli Zavascki; Marcia Andrea Buring; Marco Félix Jobim. (Org.). Diálogos Constitucionais de Direito Público e Privado. 1 ed. Porto Alegre, 2012, v. 2, p. 405-420.pag.406.

MUNHOZ, Eduardo Secchi. In: SOUZA JUNIOR, Francisco Satiro de; PITOMBO, Antonio Sergio A. de Moraes (Coord.). Comentários à lei de recuperação de empresas e falências. 2. ed. São Paulo: Revista dos Tribunais, 2007. p. 287.

Parecer 534, de 2004. Sobre o Projeto de Lei da Câmara nº 71, de 2003 (nº 4.376/93, na Casa de origem), de iniciativa do Presidente da República, que regula a recuperação judicial, a extrajudicial e a falência de devedores pessoas físicas e jurídicas que exerçam atividade econômica regida pelas leis comerciais, e dá outras providências. TEBET, Ramez apud MILANI, Mario Sergio. Lei de recuperação judicial, recuperação extrajudicial e falência comentada. São Paulo: Malheiros, 2011.

RIO GRANDE SUL. Tribunal de Justiça do Estado do Rio Grande Sul. Agravo de Instrumento n. 70045411832. Agravante: Banco do Brasil S/A. Agravado: Aeromot Industria Mecanico Metalurgica Ltda. Relator Romeu Marques Ribeiro Filho. Disponível em:<http://google8.tj.rs.gov.br/search?q=cache:www1.tjrs.jus.br/site_php/consulta/consulta_p rocesso.php\%3Fnome_comarca\%3DTribunal\%2Bde\%2BJusti\%25E7a\%26versao\%3D\%26ve rsao_fonetica\%3D1\%26tipo\%3D1\%26id_comarca\%3D700\%26num_processo_mask\%3D700 45411832\%26num_processo\%3D70045411832\%26codEmenta\%3D4575906+INSTRUMEN TO+DESPROVIDO.+++AGRAVO+DE+INSTRUMENTO+QUINTA+C\%C3\%82MARA+C $\% \mathrm{C} 3 \% \mathrm{E} 7 \mathrm{VEL}+\mathrm{N} \% \mathrm{C} 2 \% \mathrm{BA}+70045411832+\% 09 \mathrm{COMARCA}+\mathrm{DE}+\mathrm{PORTO}+\mathrm{ALEGRE} \&$ site $=$ ementario \&client=buscaTJ $\&$ access $=$ p\&ie $=U T F \&$ prox ystylesheet=buscaTJ\&output=xml_no_d td\&oe=UTF-8\&numProc=70045411832\&comarca $=$ Comarca + de+Porto +Alegre \&dtJulg=2902-2012\& relator=Romeu+Marques+Ribeiro+Filho>. Acesso em: 13 nov. 12.

SÃO PAULO. Tribunal de Justiça. Agravo de Instrumento n. 0136362-29.2011.8.26.0000, Agravante: Banco Itaú BBA S/A. Agravados: Cerâmica Gyotoku Ltda (em recuperação 
judicial) e Deloitte Touche Tohmatsu Consultores Ltda (administrador judicial). Relator: $\begin{array}{llllll}\text { Pereira Calças. São } & \text { Paulo, } 28 \text { de }\end{array}$

Disponível:<https://esaj.tjsp.jus.br/cjsg/getArquivo.do?cd

Acordao $=5709697 \& v 1$ Captcha $=$ vvxtu $>$ Acesso em: 13 nov. 2012.

São Paulo. Tribunal de Justiça. Mandado de Segurança n. 0096809.04.2013.8.26.0000. Impetrante: Oswaldo Baldin Administração e Participações S/S e outros. Impetrado: Excelentíssimo Senhor Desembargador da $1^{\mathrm{a}}$ Câmara Reservada de Direito Empresarial do Tribunal de Justiça do Estado de São Paulo. Relator: Francisco Loureiro. São Paulo, 15 de agosto de 2013.2 Disponível: http://esaj.tjsp.jus.br/cpo/sg/search.do?paginaConsulta=1\&localPesquisa.cdLocal=$1 \&$ cbPesquisa=NUMPROC $\&$ tipoNuProcesso $=$ UNIFICADO\&numeroDigitoAnoUnificado $=0$ 096809- 04.2013\&foroNumeroUnificado=0000\&dePesquisaNuUnificado=009680904.2013.8.26.0000\&dePesquisa=\&pbEnviar=Pesquisar

São Paulo. Tribunal de Justiça. Acódrão no Agravo de Instrumento $\mathrm{n}^{\circ}$ 211864125.2014.8.26.0000. Relator: Oliveira filho, PAULO FURTADO DE. Julgado em 12.08.2015. Disponível em: https://esaj.tjsp.jus.br/cjsg/getArquivo.do?cdAcordao=8715308\&cdForo=0 \&vlCaptcha=jrvhf. Acessado em 23.08.2015.

SCALZILLI, João Pedro; TELECHEA, Rodrigo; SPINELLI, Luis Felipe. Objetivos e princípios da lei de falências e recuperação de empresas. Revista Síntese Direito Empresarial, São Paulo, ano 5, n. 26, maio/jun. 2012.

VIGIL NETO, Luiz Inácio. Teoria falimentar e regimes recuperatórios estudos sobre a lei 11.101/05. Porto Alegre: Livraria do advogado, 2008. 